\title{
Circumventing Scaling Relations in Oxygen Electrochemistry Using Metal-Organic Frameworks
}

Sours, Tyler; Patel, Anjli; Nørskov, Jens ; Siahrostami, Samira; Kulkarni, Ambarish

Published in:

Journal of Physical Chemistry Letters

Link to article, DOI:

10.1021/acs.jpclett.0c02889

Publication date:

2020

Document Version

Peer reviewed version

Link back to DTU Orbit

Citation (APA):

Sours, T., Patel, A., Nørskov, J., Siahrostami, S., \& Kulkarni, A. (2020). Circumventing Scaling Relations in Oxygen Electrochemistry Using Metal-Organic Frameworks. Journal of Physical Chemistry Letters, 11, 1002910036. https://doi.org/10.1021/acs.jpclett.0c02889

\section{General rights}

Copyright and moral rights for the publications made accessible in the public portal are retained by the authors and/or other copyright owners and it is a condition of accessing publications that users recognise and abide by the legal requirements associated with these rights.

- Users may download and print one copy of any publication from the public portal for the purpose of private study or research.

- You may not further distribute the material or use it for any profit-making activity or commercial gain

- You may freely distribute the URL identifying the publication in the public portal 


\title{
Circumventing Scaling Relations in Oxygen Electrochemistry using Metal-Organic Frameworks
}

\author{
Tyler Sours, $\grave{\dagger}^{1}$ Anjli Patel, $\grave{\dagger}^{2}$ Jens Nørskov, ${ }^{3}$ Samira Siahrostami*4 and Ambarish Kulkarni*1 \\ ${ }^{1}$ Department of Chemical Engineering, University of California, Davis, Davis 95616, California, United States \\ ${ }^{2}$ SUNCAT Center for Interface Science and Catalysis, Department of Chemical Engineering, Stanford University, Stanford \\ 94305, California, United States \\ ${ }^{3}$ Department of Physics, Technical University of Denmark, 2800, Kongens Lyngby, Denmark \\ ${ }^{4}$ Department of Chemistry, University of Calgary, 2500 University Drive NW, Calgary, Alberta T2N 1N4, Canada \\ $\dagger$ equal contribution
}

Keywords: Metal-organic frameworks, oxygen reduction reaction, fuel cells

\section{Supporting Information Placeholder}

\begin{abstract}
It has been well-established that unfavorable scaling relationships between ${ }^{*} \mathrm{OOH},{ }^{*} \mathrm{OH}$, and $* \mathrm{O}$ are responsible for the high overpotentials associated with oxygen electrochemistry. A number of strategies have been proposed for breaking these linear constraints for traditional electrocatalysts (e.g. metals, alloys, metaldoped carbons); such approaches have not yet been validated experimentally for heterogenous catalysts. Development of a new class of catalysts capable of circumventing such scaling relations remains an ongoing challenge in the field. In this work, we use density functional theory (DFT) calculations to demonstrate that bimetallic porphyrin-based MOFs (PMOFs) are an ideal materials platform for rationally-designing the $3 \mathrm{D}$ active site environments for oxygen reduction reaction (ORR). Specifically, we show that the $* \mathrm{OOH}$ binding energy and the theoretical limiting potential can be optimized by appropriately tuning the transition metal active site, the oxophilic spectator, and the MOF topology. Our calculations predict theoretical limiting potentials as high as $1.07 \mathrm{~V}$ for $\mathrm{Fe} / \mathrm{Cr}-$ PMOF-Al, which exceeds the Pt/C benchmark for $4 \mathrm{e}$ ORR. More broadly, by highlighting their unique characteristics, this works aims to establish bimetallic porphyrin-based MOFs as a viable materials platform for future experimental and theoretical ORR studies.
\end{abstract}

Oxygen electrochemistry in the form of oxygen reduction reaction (ORR, for fuel cells) and oxygen evolution reaction (OER, for water electrolyzers) lies at the heart of an environmentally sustainable hydrogen-based economy. ${ }^{1}$ However, widespread adoption of these technologies has been limited due to the high cost and thermodynamic losses associated with ORR and OER electrocatalysts (referred together as OXR). Despite large research investments, only modest improvements have been achieved in the catalyst performance over the past decade; the best catalysts show onset potentials that deviate $\sim 0.3$ $-0.4 \mathrm{~V}$ away from the ideal value (i.e. $1.23 \mathrm{~V}_{\mathrm{RHE}}$ ). ${ }^{2-4}$ These losses have been attributed to the unfavorable scaling between the binding energies of OXR intermediates, in particular ${ }^{*} \mathrm{OOH}$ vs $* \mathrm{OH}^{2,5,6}$ Although recent discoveries of low-cost alternatives are encouraging, ${ }^{7,8}$ it is likely that their performance is also constrained by similar intrinsic limitations.

Despite slight material-specific variations, the robustness of the $* \mathrm{OOH}$ vs $* \mathrm{OH}$ linear correlation across different materials and computational methods is well-established. ${ }^{9,10}$ Specifically, a slope of $0.9-1.0$ is observed (due to the single bond with the surface), with an intercept of $2.9-3.2$ (due to the peroxyl bond in *OOH). ${ }^{5,11,12} \mathrm{De}$ signing materials that circumvent this linear scaling relationship is crucial for the development of the next generation of OXR electrocatalysts. ${ }^{11,13}$

A promising strategy towards this goal is the confinement of * $\mathrm{OOH}$ within a 3-D active site environment, which has been demonstrated for a few model systems and homogenous molecular catalysts. For instance, Rossmeisl et al. ${ }^{14,15}$ have shown that diporphyrin motifs are capable of facilitating ${ }^{*} \mathrm{OOH}$ dissociation via two closely-spaced binding sites. This approach bypasses the limitations imposed by *OOH scaling in favor of the less restrictive dissociated $* \mathrm{O}+* \mathrm{OH}$ pathway. Following some of the thermodynamic optimization guidelines discussed by CalleVallejo and colleagues, ${ }^{16}$ we aim to preferentially stabilize ${ }^{*} \mathrm{OOH}$ (relative to ${ }^{*} \mathrm{OH}$ ) by tuning the surrounding active site environment. 


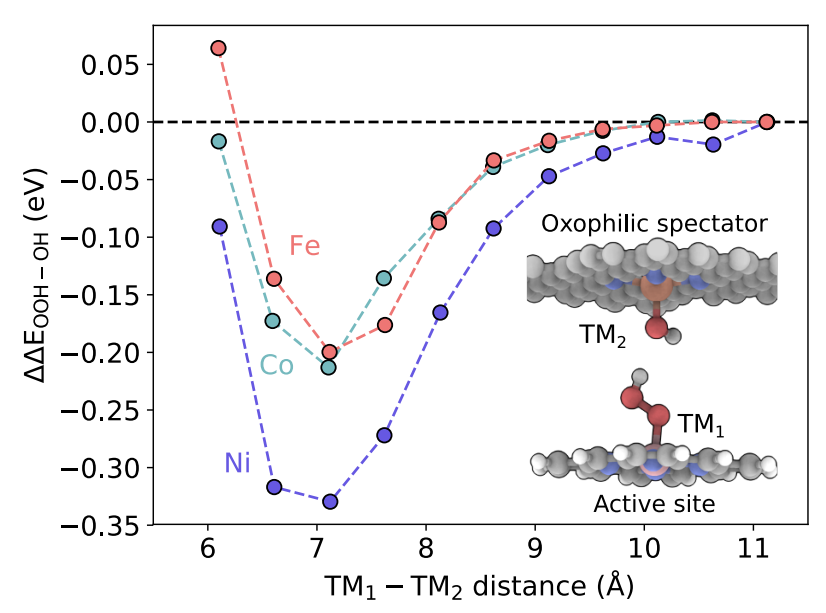

Figure 1. Preferential stabilization of $* \mathrm{OOH}$ relative to $* \mathrm{OH}$ at different distances compared to the non-interacting system for various active sites $\left(\mathrm{TM}_{1}=\mathrm{Fe}\right.$, red; $\mathrm{Co}$, light blue; $\mathrm{Ni}$, dark blue) with an oxophilic $\mathrm{Fe}-\mathrm{OH}$ spectator $\left(\mathrm{TM}_{2}\right)$. $\Delta \Delta \mathrm{E}$ оон-он $=\Delta \mathrm{E}_{\text {оон }}-\Delta \mathrm{E}_{\mathrm{OH}}$, where $\Delta \mathrm{E}_{\text {оон }}\left(\Delta \mathrm{E}_{\mathrm{OH}}\right)$ represents the stabilization of $* \mathrm{OOH}(* \mathrm{OH})$ relative to the non-interacting system at large separations.

Similar to the co-facial Pacman molecules, ${ }^{17-19}$ Fig. 1 shows a related model system consisting of two transition metals (TMs). Specifically, Fe/ $\mathrm{N}_{4}$-doped $\left(\mathrm{TM}_{2}=\mathrm{Fe}\right)$ graphene sheet is placed in close proximity with a TM porphyrin molecule $\left(\mathrm{TM}_{1}=\mathrm{Fe}, \mathrm{Co}\right.$ and $\left.\mathrm{Ni}\right)$. The Fe center embedded in the graphene acts as an inactive spectating species that preferentially stabilizes $\mathrm{TM}_{1}-{ }^{*} \mathrm{OOH}$ via hydrogen bonding interactions. An additional stabilization of $0.2-0.35 \mathrm{eV}$ is observed for $* \mathrm{OOH}$ at distances of $7.0 \AA$ (using the BEEF-vdW ${ }^{20}$ functional) compared to the non-interacting system (i.e. at large separations). Validation with other functionals (e.g. RPBE, ${ }^{21} \mathrm{BLYP},{ }^{22,23}$ $\mathrm{B} 3 \mathrm{LYP}^{24}$ and HSE06, ${ }^{25,26}$ Grimme's D3BJ ${ }^{27-29}$ ) show that the stabilization (1) is not an artifact of using a specific functional, (2) is not dominated by van der Waals interactions (Fig. S1) and (3) changes the $\mathrm{TM}_{1}-\mathrm{O}$ bond order affecting both the "slope" and the "intercept" of the scaling lines (see Fig. S2). The preferential stabilization of * $\mathrm{OOH}$ relative to $* \mathrm{OH}$ arises due to the favorable confined geometry, which provides a design principle to guide the development of active OXR catalysts.

This finding leads to an intriguing question; can we design other materials that leverage favorable spatial orientations of binding sites to circumvent OXR scaling relations? To the best of our knowledge, no heterogenous catalysts have been experimentally proven to take advantage of these effects for ORR. Within the field of electrochemistry, it is critical to translate these strategies to an experimentally-synthesizable and industrially-scalable class of materials. ${ }^{5}$

Metal-Organic Frameworks (MOFs), a class of nanoporous materials consisting of metal nodes interconnected by organic linkers, are uniquely attractive due to their experimentally realizable diversity of active sites, 3-D porous chemical environments, and topologies ${ }^{30-32}$ Although MOF electrochemistry is a relatively nascent direction, a variety of common MOFs, such as Co-PMOF$\mathrm{Al}^{33}{ }^{33} \mathrm{PCN}-223(\mathrm{Fe}),{ }^{34} \mathrm{PCN}-226(\mathrm{Co}),{ }^{35}$ and $\mathrm{Ni}-\mathrm{HAB}^{36}$ show intrinsic ORR activity. The experimental onset potentials range from $0.7-0.83 \mathrm{~V}$, which is comparable with other promising catalysts. Progress in MOF electrocatalysis, including MOF stability and charge transfer, has been summarized in a number of recent reviews. ${ }^{37-41}$

In the remainder of this work, we use periodic density functional theory (DFT) calculations to show that bimetallic porphyrin-based, mixed-linker MOFs can be designed to preferentially stabilize $* \mathrm{OOH}$. Specifically, by using a combination of active and oxophilic transition metal cations, we leverage the 3-D pore structure of MOFs to spatially orient the porphyrin binding sites and circumvent the scaling relations.

Figure $2 \mathrm{a}$ shows the structure of PMOF-A1, ${ }^{33,42}$ which consists of TCPP ligands (TCPP = tetrakis(4-carboxyphenyl)porphyrin) stacked on top of each other to form a 3-D structure connected via a 1-D Al-oxide chain. PMOF-Al is water stable and has been shown to be experimentally active for ORR. ${ }^{33}$ The spacing between the two linkers is $\sim 6.7 \AA$, which compares well with the favorable region in Fig. 1. As different linkers can be incorporated in MOFs during synthesis or using post-synthetic methods, ${ }^{43-45}$ we used DFT calculations to explore mixed-linker PMOF-Al configurations consisting of alternating $\mathrm{TM}_{1} / \mathrm{TCPP}$ and $\mathrm{TM}_{2} / \mathrm{TCPP}$ linkers $\left(\mathrm{TM}_{1}=\mathrm{Cr}\right.$, $\left.\mathrm{Mn}, \mathrm{Fe}, \mathrm{Co}, \mathrm{Ni} ; \mathrm{TM}_{2}=\mathrm{Cr}, \mathrm{Mn}, \mathrm{Fe}\right)$. Pourbaix diagrams are used to determine the coverage and oxidation states of the TMs while allowing simultaneous binding on both sides of the linker (Fig. S3). All possible spin combinations are explored to determine the lowest energy electronic structure for each TM (Table S1). Entropic corrections are calculated using the harmonic approximation (Table S2), and solvation contributions are estimated using VASPsol. ${ }^{46}$ The solvent iso-surface (Fig. S4) confirms that the solvent penetrates the MOF cavity. Other solvation approaches are possible, ${ }^{47}$ but are beyond the scope of this work. The calculated absolute and relative solvation effects are summarized in Table S3.

Figure $2 \mathrm{~b}$ shows the DFT-calculated free energy diagram for the Co active site in monometallic and bimetallic PMOF-Al using TPSSh-D3BJ ${ }^{48}$ functional. The theoretical limiting potential for the molecular $\mathrm{Co} / \mathrm{TCPP}$ analog $\left(\mathrm{U}_{\mathrm{L}}=0.52 \mathrm{~V}\right)$ is consistent with the monometallic $\mathrm{Co} / \mathrm{PMOF}$ system $\left(\mathrm{U}_{\mathrm{L}}=0.59 \mathrm{~V}\right.$, blue $)$. Our calculated limiting potentials agree reasonably with the experimentally measured half-wave potentials $(0.55 \mathrm{~V})$ and onset potentials $(0.75 \mathrm{~V}),{ }^{33}$ further confirming the suitability of the computational protocol.

Similar calculations with RPBE-D3BJ predicts incorrect spin states and TM geometry, while the HSE06-D3BJ functional under-predicts binding energies for $\mathrm{Co} / \mathrm{TCPP}$ and $\mathrm{Fe} / \mathrm{TCPP}$. These findings are inconsistent with 
experimental results and are not discussed further (see SI for details). Detailed benchmarking of different function-

(a)

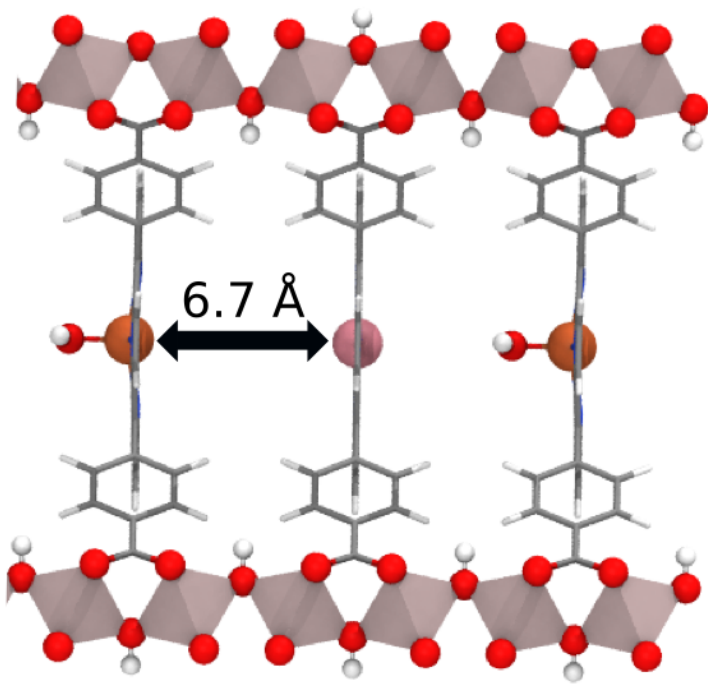

(b)

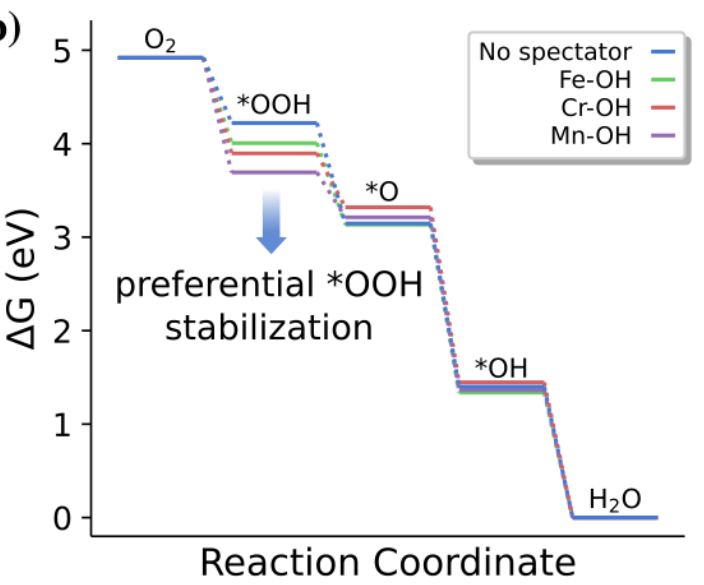

Figure 2. (a) Structure of bimetallic PMOF-Al with Co active site and $\mathrm{Fe}-\mathrm{OH}$ spectator, (b) Free energy diagram (TPSSh-D3BJ) showing the preferential stabilization of * $\mathrm{OOH}$. Color scheme: Co (pink), Fe (brown), C (grey), O (red), and $\mathrm{H}$ (white).

als (e.g. $\omega \mathrm{B} 97,{ }^{49} \mathrm{MN} 15^{50}$ ) with coupled cluster theory and/or multireference methods for various transition metals is beyond the scope of this work. ${ }^{47,51-53}$

Compared to Co-PMOF-Al with no spectator, Fig. $2 \mathrm{~b}$ shows that the presence of an oxophilic spectator $(\mathrm{Fe}-\mathrm{OH}$, green) improves the predicted activity. For instance, the theoretical limiting potential for the bimetallic $\mathrm{Co} / \mathrm{Fe}$ $\mathrm{OH} / \mathrm{PMOF}-\mathrm{Al}$ catalyst $(0.81 \mathrm{~V})$ is comparable to the $\mathrm{Pt} / \mathrm{C}$ benchmark $\left(\mathrm{U}_{\mathrm{L}}=0.8 \mathrm{~V}\right)$. The improved activity originates from the additional $0.22 \mathrm{eV}$ stabilization of $* \mathrm{OOH}$ due to the presence of the Fe-OH spectator. Simulations of other oxophilic TMs (see $\mathrm{Mn}-\mathrm{OH}$ and $\mathrm{Cr}-\mathrm{OH}$ in Fig. $2 b)$ confirm that the presence of the spectator ligand significantly affects *OOH binding; the other OXR adsorbates (i.e. ${ }^{*} \mathrm{OH}$ and $* \mathrm{O}$ ) are largely unaffected.
While the above discussion is limited to the Co active site, we perform additional DFT calculations with $\mathrm{Ni}, \mathrm{Fe}, \mathrm{Cr}$, and $\mathrm{Mn}$ active sites. For each TM, the most stable coverage predicted by the Pourbaix diagram is used (e.g. Cr$\mathrm{OH}, \mathrm{Mn}-\mathrm{OH})$. As shown in Fig. 3a, we predict similar scaling slopes for TCPP $(0.66$, orange $)$ and monometallic PMOF-Al $(0.60$, blue). The deviation from unity likely arises due to the changes in the spin states for ${ }^{*} \mathrm{OOH}$ and * $\mathrm{OH}$ intermediates and differences in the active site coordination geometry (e.g. square planar Co vs. distorted square pyramidal $\mathrm{Cr}-\mathrm{OH})$.

More interestingly, the presence of the $\mathrm{Fe}-\mathrm{OH}$ spectator results in a favorable deviation from the above scaling behavior. Specifically, we observe a preferential ${ }^{*} \mathrm{OOH}$ stabilization of up to $0.4 \mathrm{eV}$ for various TM active sites (Fig. S5). A smaller deviation is observed for strongly binding TMs (e.g. Fe-* ${ }^{*} \mathrm{OH}, 0.07 \mathrm{eV}$ ). In contrast, weakly binding TMs (e.g. Ni- $\left.{ }^{*} \mathrm{OOH}\right)$ are stabilized to a larger extent $(0.39 \mathrm{eV})$. For a given TM active site, the extent of $* \mathrm{OOH}$ stabilization also depends on the identity of the spectator. For instance, Mn-OH spectator (purple, Fig. 3a) results in systematically higher stabilization than $\mathrm{Fe}-\mathrm{OH}$ spectator. In all cases, the $* \mathrm{O}$ and $* \mathrm{OH}$ binding energies do not change significantly $(<0.15 \mathrm{eV})$.

The trends in $* \mathrm{OOH}$ stabilization can be explained by the increasing electronegativity of the spectating metal (Mn $<\mathrm{Cr}<\mathrm{Fe}$ ). Spectating metals with lower electronegativity allow for more charge to be localized on the spectator ligand $(\mathrm{OH})$, resulting in a stronger hydrogen bond and increased stability of the * $\mathrm{OOH}$ intermediate. Table S4 shows the differences in the calculated bond orders for Co active site with different spectators. In particular, the $\mathrm{H}_{\mathrm{OOH}}-\mathrm{O}_{\mathrm{OH}}$ bond order increases from 0.23 (Fe-OH spectator) to 0.33 (Mn-OH spectator) confirming a stronger hydrogen bond. Bond order analysis also reveals that the presence of the spectator localizes more charge on the * $\mathrm{OOH}$ adsorbate compared to the no spectator system. The $\mathrm{Co}-\mathrm{O}_{\mathrm{OOH}}$ bond order decreases from 0.57 to 0.48 with the Mn-OH spectator. Although the weakened TMoxygen bond may favor the 2e pathway, detailed investigation of kinetic effects and product selectivity (i.e. $\mathrm{H}_{2} \mathrm{O}_{2}$ vs. $\mathrm{H}_{2} \mathrm{O}$ ) is beyond the scope of this work.

As the spectator stabilizes $* \mathrm{OOH}$, the improvement in the ORR limiting potential is well-explained by the 1-D volcano plot in Fig. 3b. Specifically, for TMs that lie on the right leg of the volcano (i.e. activity is limited by $\mathrm{O}_{2} \rightarrow$ $* \mathrm{OOH})$, the spectator stabilizes $* \mathrm{OOH}$, improves the *OOH vs. ${ }^{*} \mathrm{OH}$ scaling, and favorably shifts the right leg of the volcano. This is depicted by black arrows in Fig. $3 \mathrm{~b}$ corresponding to an improvement in the activity of $\mathrm{Co}$ and $\mathrm{Cr}-\mathrm{OH}$ active sites due to the $\mathrm{Fe}-\mathrm{OH}$ spectator (green line, filled symbols) compared to the no spectator case (black line, empty symbols). The predicted limiting potential for the bimetallic $\mathrm{Cr} / \mathrm{Fe}-\mathrm{PMOF}-\mathrm{Al}$ catalyst is 1.07 $\mathrm{V}$, which exceeds the performance of the benchmark Pt/C 

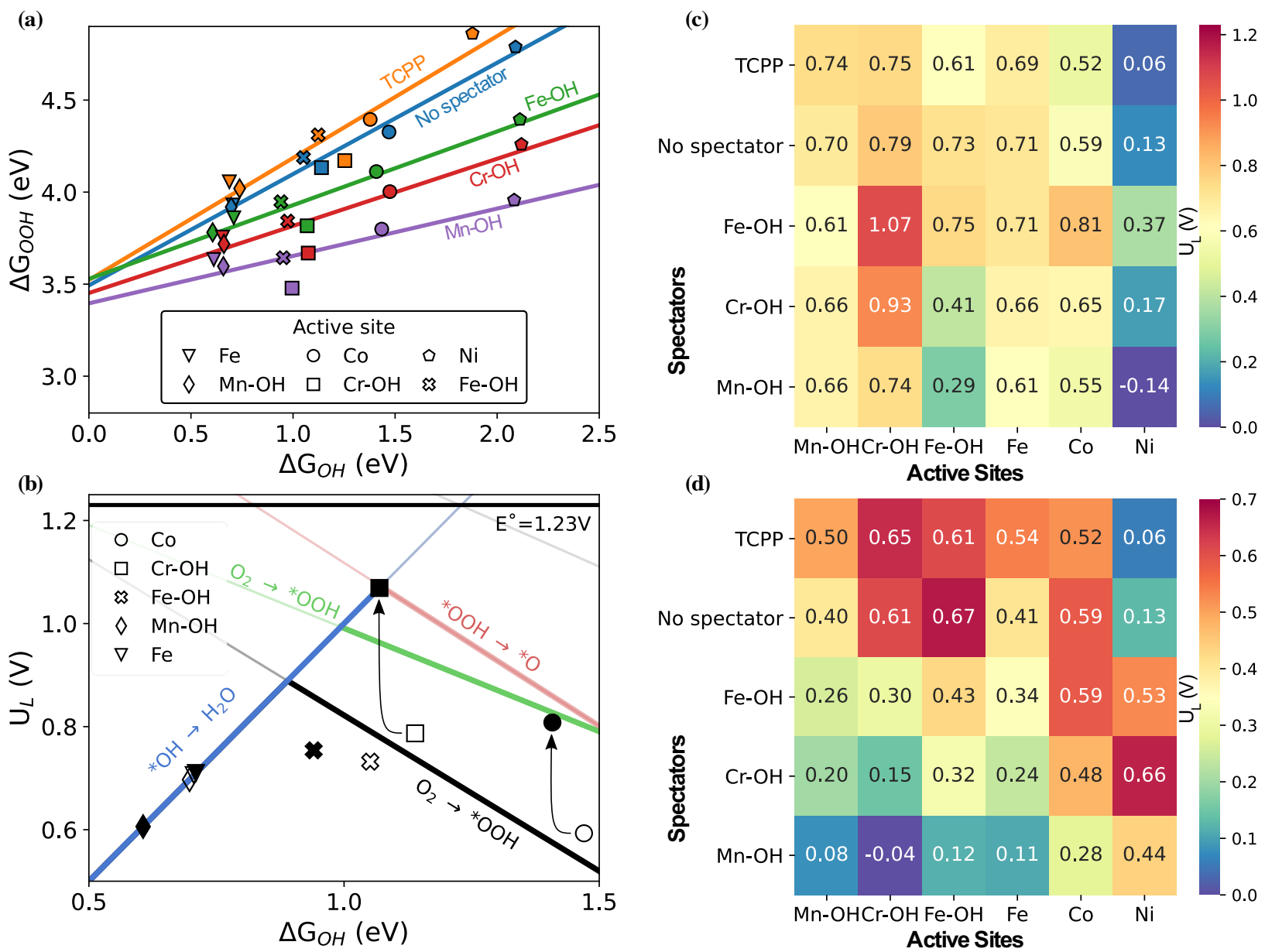

Figure 3. (a) Comparison of $* \mathrm{OOH}$ vs. ${ }^{*} \mathrm{OH}$ scaling lines for TCPP, monometallic and bimetallic PMOF-Al with different active sites and spectators, (b) 1-D volcano plot showing the improvement in activity (black arrows) due to the presence of Fe$\mathrm{OH}$ spectator (filled symbols) compared to the no spectator (empty symbols) scenario. TPSSh-D3BJ calculated limiting potential for (c) 4e and (d) 2e ORR for various bimetallic MOFs.

catalyst $\left(\mathrm{U}_{\mathrm{L}}=0.8 \mathrm{eV}\right)$. TPSSh-D3BJ suggests $\mathrm{Cr}-\mathrm{OH}$ active site possesses high activity for all spectator combinations, and the limiting potentials for $\mathrm{Cr}-\mathrm{OH}$ TCPP $(0.75$ $\mathrm{V})$ and no spectator $(0.79 \mathrm{~V})$ agree very well with the experimental half-wave potential $(0.77 \mathrm{~V})$ of a recently reported $\mathrm{Cr}-\mathrm{N}_{4}$ catalyst. ${ }^{54}$

These results are further summarized in the heat-map in Fig. 3c, which includes $\mathrm{Mn}-\mathrm{OH}$ and $\mathrm{Cr}-\mathrm{OH}$ spectators. While $\mathrm{Fe}-\mathrm{OH}$ spectator tends to improve the 4e limiting potentials, $\mathrm{Mn}-\mathrm{OH}$ and $\mathrm{Cr}-\mathrm{OH}$ do not have the same effect. Specifically, $\mathrm{Mn}-\mathrm{OH}$ and $\mathrm{Cr}-\mathrm{OH}$ overstabilize $* \mathrm{OOH}$, and the activity becomes limited by the ${ }^{*} \mathrm{OOH} \rightarrow$ *O step (see 1-D volcanoes in Fig. S6).

As the $* \mathrm{OOH} \rightarrow * \mathrm{O}$ step is often not limiting for metals and alloys, we emphasize that molecular and MOF-based ORR catalysts require a more careful analysis beyond the traditional $* \mathrm{OOH}$ vs $* \mathrm{OH}$ scaling for metals and alloys. Single atom $\mathrm{M}-\mathrm{N}_{4}$ catalysts only allow binding of the $* \mathrm{O}$ intermediate at the on-top site (as opposed to the more favorable hollow sites for metallic surfaces), which has already been shown to destabilize binding of $* 0 .{ }^{55}$ This destabilization of $* \mathrm{O}$ combined with overstabilization of $* \mathrm{OOH}$ presents a new bottleneck for $4 \mathrm{e}$ ORR, where formation of $* \mathrm{O}$ from $* \mathrm{OOH}$ limits the achievable potential. While these effects are observed in all bimetallic combinations, the moderate stabilization of $* \mathrm{OOH}$ due to Fe$\mathrm{OH}$ spectator allows for an improvement in theoretical overpotential, notably for the $\mathrm{Co}$ and $\mathrm{Cr}-\mathrm{OH}$ active center. However, stronger stabilization seen with $\mathrm{Mn}-\mathrm{OH}$ and $\mathrm{Cr}-$ $\mathrm{OH}$ spectators yields a reduction in catalytic performance as $* \mathrm{OOH}$ is stabilized to the point where ${ }^{*} \mathrm{O}$ formation is unfavorable.

Recognizing that this $* \mathrm{O}$ destabilization relative to metal surfaces may compromise the selectivity of these systems towards the $4 \mathrm{e}$ reduction to water, we extend our analysis to the $2 \mathrm{e}$ oxygen reduction reaction to form hydrogen peroxide. Figure 3d summarizes the calculated 2e limiting potentials for all active site and spectator combinations. As expected, for stronger binding active sites that lie on the left leg of the volcano (e.g. Mn-OH), incorporation of an oxophilic spectator overstabilizes $* \mathrm{OOH}$ and reduces the 2e ORR activity. However, for weakly binding metals on the far right of the volcano, a noticeable improvement 
(a)

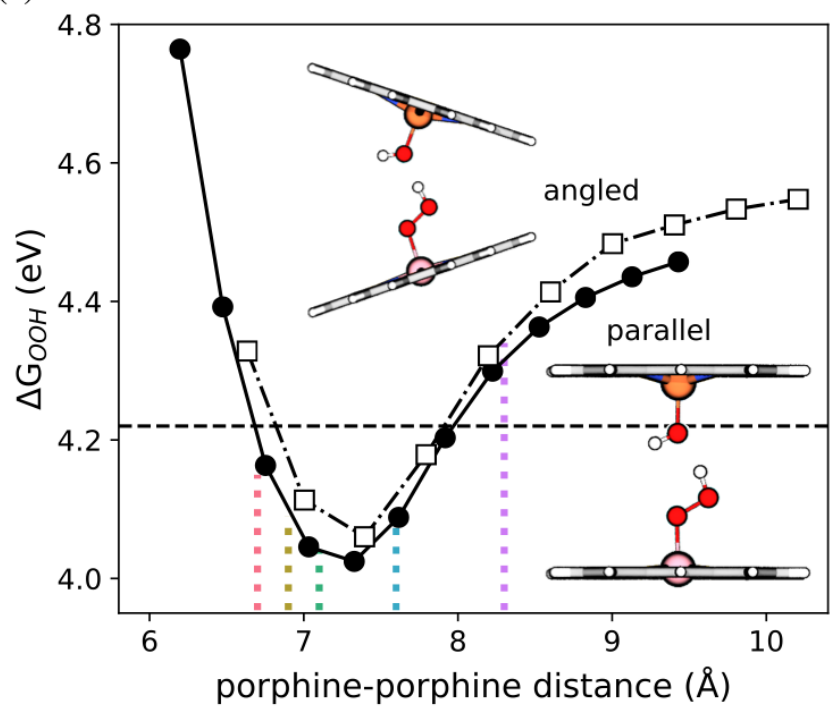

(b)

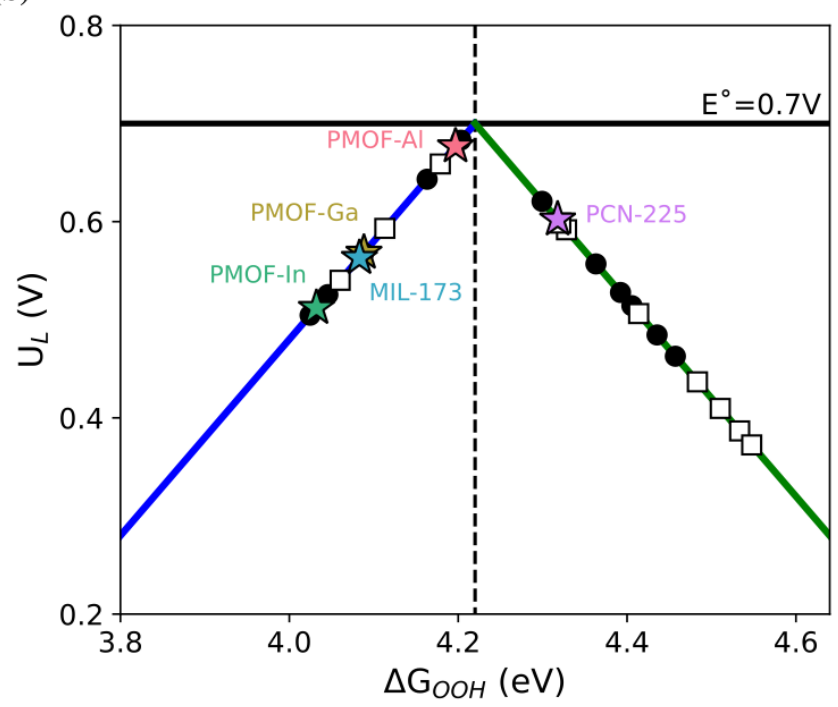

Figure 4. (a) The * $\mathrm{OOH}$ binding energy for the two parallel (filled circles) and angled (empty squares) interacting porphine molecules at various distances, (b) TPSSh-D3BJ calculated 2e limiting potentials for the model systems. Limiting potentials for PMOF-Al (red), PMOF-Ga (yellow), PMOF-In (green), MIL-173 (blue), and PCN-225 (purple) are predicted from their measured porphyrin separation distance.

in theoretical limiting potential is obtained. For the Ni active site, TPSSh-D3BJ predicts highly active limiting potentials of $0.53(0.66) \mathrm{V}$ when combined with $\mathrm{Fe}-\mathrm{OH}$ $(\mathrm{CrOH})$ spectators, which represents a $0.4 \mathrm{eV}$ improvement over the no spectator scenario.

The above results indicate that porphyrin-based MOFs are a promising platform for tuning the binding energies of OXR adsorbates. Unlike metals and alloys where only the composition ${ }^{56}$ or strain $^{57}$ can be varied, the 3-D active sites in MOFs offer unique degree of control that is unavailable in other materials. Specifically, in addition to appropriately choosing the bimetallic system (i.e. $\mathrm{TM}_{1}$ and $\mathrm{TM}_{2}$ ), we can now potentially design MOF topologies to further tune the adsorbate binding energies for OXR.

As an illustrative example, we consider a model system consisting of two interacting porphine molecules (Co active site, $\mathrm{Fe}-\mathrm{OH}$ spectator) at varying distances. As shown in Fig. 4a, parallel configurations can be considered as analogs of PMOF-Al with different 1-D metal oxide chains (e.g. substituting $\mathrm{Al}$ with $\mathrm{Ga}$ or $\mathrm{In}^{58}$ ), or other similar rod-based MOFs, such as MIL-173. ${ }^{59}$ Additionally, a pair of angled $\left(37^{\circ}\right)$ porphines is chosen to mimic the topology of the porphyrinic $\mathrm{Zr}_{6}$-Oxo cluster MOF, PCN$225 .^{60}$ The distance between the TMs is varied to illustrate the reticular approach in MOF synthesis, ${ }^{61}$ we demonstrate the effects of varying the linker size while retaining the same topology. Fig. 4a shows a high degree of control on reaction thermodynamics can be achieved by tuning the separation distance between adjacent porphyrin motifs, and the distances of several known MOFs are highlighted with vertical dotted lines. For both the parallel and angled configurations, shorter distances $(\sim 7 \AA)$ enable stronger $* \mathrm{OOH}$ stabilization that suggest a preference towards 4e ORR. Interestingly, TPSSh-D3BJ predicts a range of $* \mathrm{OOH}$ binding energies that encompass the $2 \mathrm{e}$ ORR optimum (4.2 eV, dashed black line in Fig. 4). For the model systems considered here, we find that intrinsic catalytic activity is insensitive to small topological changes in porphyrin orientation (i.e. parallel versus angled). These results show that weakly $* \mathrm{OOH}$ binding active sites can be optimized for 2e peroxide synthesis by appropriately choosing the spectator transition metal, optimizing the $\mathrm{TM}_{1}-\mathrm{TM}_{2}$ separation, and changing the $\mathrm{MOF}$ topology. We acknowledge that these results alone are not conclusive of reaction selectivity; detailed kinetic studies and experimental measurements are necessary to validate our predictions.

By using state-of-the-art DFT calculations, we have demonstrated that porphyrin-based MOFs are an ideal materials platform for rationally designing $3-\mathrm{D}$ active site environments for ORR. To the best of our knowledge, these computational predictions represent the first experimentally-synthesizable heterogenous catalysts (i.e. MOFs) where the 3-D structure of the active site can be intentionally designed to circumvent the ${ }^{*} \mathrm{OOH}$ vs. ${ }^{*} \mathrm{OH}$ scaling relations. Other factors that impact the efficacy of MOF electrocatalysts, such as charge transport, ${ }^{62-65}$ counterion and substrate diffusion, ${ }^{64,65}$ explicit solvation, ${ }^{47}$ etc. represent ongoing research directions in the group. We anticipate that this work will motivate further computational studies and experimental validation of MOF-based electrocatalysts for ORR.

\section{COMPUTATIONAL METHODS}

Periodic density functional theory (DFT) calculations are performed using the projector augmented wave method 
as implemented in the Vienna ab initio simulation package (VASP). All energies are calculated using a $400 \mathrm{eV}$ plane-wave cutoff. Only the $\Gamma$-point is sampled owing to the large MOF unit cells. A range of generalized gradient approximation (BEEF-vdW, ${ }^{20} \mathrm{BLYP}^{22,23} \mathrm{RPBE}^{21}$ ) and hybrid (B3LYP, ${ }^{24}$ HSE06, ${ }^{25,26}$ and TPSSh $^{48}$ ) functionals are used to examine the sensitivity of our results. Dispersion corrections are considered using the DFT-D3 method with Becke-Johnson damping. ${ }^{27-29}$ Electronic energies are converged to $10^{-6} \mathrm{eV}$. All structures are relaxed until the forces are less than $0.03 \mathrm{eV} / \AA$ for RPBE and $0.1 \mathrm{eV} / \AA$ for HSE06 and TPSSh. A lower threshold is used for the hybrid functionals owing to the high computational costs; differences in binding energies are less than $0.01 \mathrm{eV}$. All possible spin states are considered. Implicit solvation corrections are implemented using VASPSol. ${ }^{46}$ The finite displacement method $(0.015 \AA)$ is used to calculate the entropic corrections and zero-point energies. Bond orders are calculated using the density derived electrostatic and chemical (DDEC) charge method. ${ }^{66,67}$

\section{ASSOCIATED CONTENT}

Supporting Information. DFT optimized structures are available as ase-db files.

\section{AUTHOR INFORMATION}

\section{Corresponding Author}

Samira Siahrostami: samira.siahrostami@ucalgary.ca, Ambarish Kulkarni: arkulkarni@ucdavis.edu

\section{Author Contributions}

TS and AP contributed equally to this work.

\section{Funding Sources}

TS and AK are partially supported by startup funds provided by University of California, Davis. AP, AK, SS and JKN acknowledge partial support from the Toyota Research Institute. AP acknowledges partial support from the National Science Foundation Graduate Research Fellowship Program.

\section{ACKNOWLEDGMENT}

We are grateful to the computational resources provided by Extreme Science and Engineering Discovery Environment (XSEDE), which is supported by National Science Foundation grant number ACI-1548562 and National Energy Research Scientific Computing Center (NERSC), a U.S. Department of Energy Office of Science User Facility operated under Contract No. DE-AC02-05CH11231.

\section{REFERENCES}

(1) Debe, M. K. Electrocatalyst Approaches and Challenges for Automotive Fuel Cells. Nature 2012, 486 (7401), 43-51. https://doi.org/10.1038/nature11115.

(2) Seh, Z. W.; Kibsgaard, J.; Dickens, C. F.; Chorkendorff, I.; Nørskov, J. K.; Jaramillo, T. F. Combining Theory and Experiment in Electrocatalysis: Insights into Materials Design. Science (80-.). 2017, 355 (6321). https://doi.org/10.1126/science.aad4998. Catalysts with Improved Oxygen Reduction Activity in Polyme

)
Wellendorff, J.; Silbaugh, T. L.; Garcia-Pintos, D.; Nørskov, J. K.; Bligaard, T.; Studt, F.; Campbell, C. T. A Benchmark Database for Adsorption Bond Energies to Transition Metal Surfaces and Comparison to Selected $\{$ DFT $\}$ Functionals. Surf.

Electrolyte Fuel Cells. Science (80-. ). 2009, 324 (5923), 71-74. https://doi.org/10.1126/science.1170051.

Li, J.; Chen, M.; Cullen, D. A.; Hwang, S.; Wang, M.; Li, B.; Liu, K.; Karakalos, S.; Lucero, M.; Zhang, H.; Lei, C.; Xu, H.; Sterbinsky, G. E.; Feng, Z.; Su, D.; More, K. L.; Wang, G.; Wang, Z.; Wu, G. Atomically Dispersed Manganese Catalysts for Oxygen Reduction in Proton-Exchange Membrane Fuel Cells. Nat. Catal. 2018, 1 (12), 935-945. https://doi.org/10.1038/s41929-018-0164-8.

Kulkarni, A.; Siahrostami, S.; Patel, A.; Nørskov, J. K. Understanding Catalytic Activity Trends in the Oxygen Reduction Reaction. Chemical Reviews. 2018, pp 2302-2312. https://doi.org/10.1021/acs.chemrev.7b00488.

Nørskov, J. K.; Rossmeisı, J.; Logadottir, A.; Lindqvist, L.; Lyngby, D.-; Jo, H. Origin of the Overpotential for Oxygen Reduction at a Fuel-Cell Cathode. 2004, 17886-17892. https://doi.org/10.1021/jp047349j.

Chen, Y.; Ji, S.; Chen, C.; Peng, Q.; Wang, D.; Li, Y. SingleAtom Catalysts: Synthetic Strategies and Electrochemical Applications. Joule 2018, 2 (7), 1242-1264. https://doi.org/10.1016/j.joule.2018.06.019.

Wan, C.; Duan, X.; Huang, Y. Molecular Design of SingleAtom Catalysts for Oxygen Reduction Reaction. Adv. Energy Mater. 2020, 10 (14), 1-19.

https://doi.org/10.1002/aenm.201903815.

Christensen, R.; Hansen, H. A.; Dickens, C. F.; Nørskov, J. K.; Vegge, T. Functional Independent Scaling Relation for ORR/OER Catalysts. J. Phys. Chem. C 2016, 120 (43), 2491024916. https://doi.org/10.1021/acs.jpcc.6b09141.

Song, F.; Bai, L.; Moysiadou, A.; Lee, S.; Hu, C.; Liardet, L.; $\mathrm{Hu}, \mathrm{X}$. Transition Metal Oxides as Electrocatalysts for the Oxygen Evolution Reaction in Alkaline Solutions: An Application-Inspired Renaissance. J. Am. Chem. Soc. 2018, 140 (25), 7748-7759. https://doi.org/10.1021/jacs.8b04546. Calle-Vallejo, F.; Martínez, J. I.; Rossmeisl, J. Density Functional Studies of Functionalized Graphitic Materials with Late Transition Metals for Oxygen Reduction Reactions. Phys. Chem. Chem. Phys. 2011, 13 (34), 15639-15643. https://doi.org/10.1039/c1cp21228a.

Man, I. C.; Su, H. Y.; Calle-Vallejo, F.; Hansen, H. A.; Martínez, J. I.; Inoglu, N. G.; Kitchin, J.; Jaramillo, T. F.; Nørskov, J. K.; Rossmeisl, J. Universality in Oxygen Evolution Electrocatalysis on Oxide Surfaces. ChemCatChem 2011, 3 (7), 1159-1165. https://doi.org/10.1002/cctc.201000397.

Vojvodic, A.; Nørskov, J. K. New Design Paradigm for Heterogeneous Catalysts. Natl. Sci. Rev. 2015, 2 (2), 140-143. https://doi.org/10.1093/nsr/nwv023.

Wan, H.; Østergaard, T. M.; Arnarson, L.; Rossmeisl, J. Climbing the 3D Volcano for the Oxygen Reduction Reaction Using Porphyrin Motifs. ACS Sustain. Chem. Eng. 2019, 7 (1), 611-617. https://doi.org/10.1021/acssuschemeng.8b04173. Wan, H.; Jensen, A.; Escudero-Escribano, M.; Rossmeisl, J. Insights in the Oxygen Reduction Reaction: From Metallic Electrocatalysts to Diporphyrines. ACS Catal. 2020, acscatal.0c01085. https://doi.org/10.1021/acscatal.0c01085. Govindarajan, N.; Koper, M. T. M.; Meijer, E. J.; Calle-Vallejo, F. Outlining the Scaling-Based and Scaling-Free Optimization of Electrocatalysts. ACS Catal. 2019, acscatal.9b00532. https://doi.org/10.1021/acscatal.9b00532.

Chang, C. K.; Liu, H. Y.; Abdalmuhdi, I.; Liu, H. Y.

Electroreduction of Oxygen by Pillared Cobalt Cofacial Diporphyrin Catalysts. J. Am. Chem. Soc. 1984, 106 (9), 27252726. https://doi.org/10.1021/ja00321a055.

Collman, J. P.; Wagenknecht, P. S.; Hutchison, J. E. Molecular Catalysts for Multielectron Redox Reactions of Small Molecules: The "Cofacial Metallodiporphyrin" Approach. Angew. Chemie Int. Ed. English 1994, 33 (15-16), 1537-1554. https://doi.org/10.1002/anie.199415371.

Rosenthal, J.; Nocera, D. G. Role of Proton-Coupled Electron Transfer in O-O Bond Activation. Acc. Chem. Res. 2007, 40 (7), 
Sci. 2015, 640, 36-44.

https://doi.org/10.1016/j.susc.2015.03.023

, Improved

Adsorption Energetics within Density-Functional Theory Using Revised Perdew-Burke-Ernzerhof Functionals. Phys. Rev. B Condens. Matter Mater. Phys. 1999, 59 (11), 7413-7421. https://doi.org/10.1103/PhysRevB.59.7413.

(22) Becke, A. D. Density-Functional Exchange-Energy

Approximation with Correct Asymptotic Behavior. Phys. Rev. A 1988, 38 (6), 3098-3100.

https://doi.org/10.1103/PhysRevA.38.3098.

(23) Lee, C.; Yang, W.; Parr, R. G. Development of the ColleSalvetti Correlation-Energy Formula into a Functional of the Electron Density. Phys. Rev. B 1988, 37 (2), 785-789. https://doi.org/10.1103/PhysRevB.37.785.

(24) Stephens, P. J.; Devlin, F. J.; Chabalowski, C. F.; Frisch, M. J. $\mathrm{Ab}$ Initio Calculation of Vibrational Absorption and Circular Dichroism Spectra Using Density Functional Force Fields. $J$. Phys. Chem. 1994, 98 (45), 11623-11627. https://doi.org/10.1021/j100096a001.

(25) Heyd, J.; Scuseria, G. E.; Ernzerhof, M. Hybrid Functionals Based on a Screened Coulomb Potential. J. Chem. Phys. 2003 118 (18), 8207-8215. https://doi.org/10.1063/1.1564060.

(26) Krukau, A. V.; Vydrov, O. A.; Izmaylov, A. F.; Scuseria, G. E. Influence of the Exchange Screening Parameter on the Performance of Screened Hybrid Functionals. J. Chem. Phys. 2006, 125 (22). https://doi.org/10.1063/1.2404663.

(27) Grimme, S.; Antony, J.; Ehrlich, S.; Krieg, H. A Consistent and Accurate Ab Initio Parametrization of Density Functional Dispersion Correction (DFT-D) for the 94 Elements H-Pu. $J$. Chem. Phys. 2010, 132 (15). https://doi.org/10.1063/1.3382344.

(28) Grimme, S.; Ehrlich, S.; Goerigk, L. Effect of the Damping Function in Dispersion Corrected Density Functional Theory. $J$. Comput. Chem. 2011, 32 (7), 1456-1465.

https://doi.org/10.1002/jcc.21759.

(29) Smith, D. G. A.; Burns, L. A.; Patkowski, K.; Sherrill, C. D. Revised Damping Parameters for the D3 Dispersion Correction to Density Functional Theory. J. Phys. Chem. Lett. 2016, 7 (12), 2197-2203. https://doi.org/10.1021/acs.jpclett.6b00780.

(30) Tranchemontagne, D. J.; Tranchemontagne, J. L.; O'keeffe, M.; Yaghi, O. M. Secondary Building Units, Nets and Bonding in the Chemistry of Metal-Organic Frameworks. Chem. Soc. Rev. 2009, 38 (5), 1257-1283. https://doi.org/10.1039/b817735j.

(31) Schoedel, A.; Li, M.; Li, D.; O’Keeffe, M.; Yaghi, O. M. Structures of Metal-Organic Frameworks with Rod Secondary Building Units. Chem. Rev. 2016, 116 (19), 12466-12535. https://doi.org/10.1021/acs.chemrev.6b00346.

(32) Lu, W.; Wei, Z.; Gu, Z. Y.; Liu, T. F.; Park, J.; Park, J.; Tian, J.; Zhang, M.; Zhang, Q.; Gentle, T.; Bosch, M.; Zhou, H. C. Tuning the Structure and Function of Metal-Organic Frameworks via Linker Design. Chem. Soc. Rev. 2014, 43 (16), 5561-5593. https://doi.org/10.1039/c4cs00003j.

(33) Lions, M.; Tomasino, J.-B.; Chattot, R.; Abeykoon, B.; Guillou, N.; Devic, T.; Demessence, A.; Cardenas, L.; Maillard, F.; Fateeva, A.; Tommasino, J.-B.; Chattot, R.; Abeykoon, B.; Guillou, N.; Devic, T.; Demessence, A.; Cardenas, L.; Maillard, F.; Fateeva, A. Insights into the Mechanism of Electrocatalysis of Oxygen Reduction Reaction by a Porphyrinic Metal Organic Framework. Chem. Commun. 2017, 53 (48), 6496-6499. https://doi.org/10.1039/C7CC02113E.

(34) Usov, P. M.; Huffman, B.; Epley, C. C.; Kessinger, M. C.; Zhu, J.; Maza, W. A.; Morris, A. J. Study of Electrocatalytic Properties of Metal-Organic Framework PCN-223 for the Oxygen Reduction Reaction. ACS Appl. Mater. Interfaces 2017, 9 (39), 33539-33543. https://doi.org/10.1021/acsami.7b01547.

(35) Cichocka, M. O.; Liang, Z.; Feng, D.; Back, S.; Wang, X.; Samperisi, L.; Sun, Y.; Xu, H. A Porphyrinic Zirconium MetalOrganic Framework for Oxygen Reduction Reaction : Tailoring the Spacing between Active-Sites through Chain-Based Inorganic Building Units A Porphyrinic Zirconium MetalOrganic Framework for Oxygen Reduction Reaction : Tailori. 2020. https://doi.org/10.1021/jacs.0c06329.

(36) Miner, E. M.; Fukushima, T.; Sheberla, D.; Sun, L.; Surendranath, Y.; Dinca, M. Electrochemical Oxygen Reduction Catalysed by Ni3(Hexaiminotriphenylene)2. Nat. Commun.
2016, 1-7. https://doi.org/10.1038/ncomms 10942.

Wang, W.; Xu, X.; Zhou, W.; Shao, Z. Recent Progress in Metal-Organic Frameworks for Applications in Electrocatalytic and Photocatalytic Water Splitting. Advanced Science. 2017. https://doi.org/10.1002/advs.201600371.

Xu, Y.; Li, Q.; Xue, H.; Pang, H. Metal-Organic Frameworks for Direct Electrochemical Applications. Coord. Chem. Rev. 2018, 376, 292-318.

https://doi.org/https://doi.org/10.1016/j.ccr.2018.08.010. D’Alessandro, D. M. Exploiting Redox Activity in MetalOrganic Frameworks: Concepts, Trends and Perspectives. Chem. Commun. 2016, 52 (58), 8957-8971. https://doi.org/10.1039/c6cc00805d.

Solomon, M. B.; Church, T. L.; D’Alessandro, D. M. Perspectives on Metal-Organic Frameworks with Intrinsic Electrocatalytic Activity. CrystEngComm 2017. https://doi.org/10.1039/C7CE00215G.

Downes, C. A.; Marinescu, S. C. Electrocatalytic Metal-Organic Frameworks for Energy Applications. ChemSusChem 2017, 10 (22), 4374-4392. https://doi.org/10.1002/cssc.201701420. Fateeva, A.; Chater, P. A.; Ireland, C. P.; Tahir, A. A.; Khimyak, Y. Z.; Wiper, P. V; Darwent, J. R.; Rosseinsky, M. J. A Water-Stable Porphyrin-Based Metal-Organic Framework Active for Visible-Light Photocatalysis. Angew. Chemie Int. Ed. 2012, 51 (30), 7440-7444.

https://doi.org/10.1002/anie.201202471.

Wang, Z.; Cohen, S. M. Postsynthetic Modification of MetalOrganic Frameworks. Chem. Soc. Rev. 2009, 38 (5), 1315-1329. https://doi.org/10.1039/b802258p.

Tanabe, K. K.; Cohen, S. M. Postsynthetic Modification of Metal-Organic Frameworks - a Progress Report. Chem. Soc. Rev. 2011, 40 (2), 498-519. https://doi.org/10.1039/c0cs00031k. Kim, M.; Cahill, J. F.; Su, Y.; Prather, K. A.; Cohen, S. M. Postsynthetic Ligand Exchange as a Route to Functionalization of "inert" Metal-Organic Frameworks. Chem. Sci. 2012, 3 (1), 126-130. https://doi.org/10.1039/c1sc00394a.

Mathew, K.; Hennig, R. G. Implicit Self-Consistent Description of Electrolyte in Plane-Wave Density-Functional Theory. 2016, $1-6$.

Patel, A. M.; Ringe, S.; Siahrostami, S.; Bajdich, M.; Nørskov, J. K.; Kulkarni, A. R. Theoretical Approaches to Describing the Oxygen Reduction Reaction Activity of Single-Atom Catalysts. J. Phys. Chem. C 2018, 122 (51), 29307-29318.

https://doi.org/10.1021/acs.jpcc.8b09430.

Staroverov, V. N.; Scuseria, G. E.; Tao, J.; Perdew, J. P. Comparative Assessment of a New Nonempirical Density Functional: Molecules and Hydrogen-Bonded Complexes. $J$. Chem. Phys. 2003, 119 (23), 12129-12137. https://doi.org/10.1063/1.1626543.

Chai, J. Da; Head-Gordon, M. Systematic Optimization of Long-Range Corrected Hybrid Density Functionals. J. Chem. Phys. 2008, 128 (8). https://doi.org/10.1063/1.2834918. Yu, H. S.; He, X.; Li, S. L.; Truhlar, D. G. MN15: A KohnSham Global-Hybrid Exchange-Correlation Density Functional with Broad Accuracy for Multi-Reference and Single-Reference Systems and Noncovalent Interactions. Chem. Sci. 2016, 7 (8), 5032-5051. https://doi.org/10.1039/c6sc00705h.

Gaggioli, C. A.; Stoneburner, S. J.; Cramer, C. J.; Gagliardi, L. Beyond Density Functional Theory: The Multiconfigurational Approach to Model Heterogeneous Catalysis. ACS Catal. 2019, 9 (9), 8481-8502. https://doi.org/10.1021/acscatal.9b01775. Radoń, M.; Pierloot, K. Binding of CO, NO, and O2 to Heme by Density Functional and Multireference Ab Initio Calculations. $J$. Phys. Chem. A 2008, 112 (46), 11824-11832.

https://doi.org/10.1021/jp806075b.

Radoń, M. Spin-State Energetics of Heme-Related Models from DFT and Coupled Cluster Calculations. J. Chem. Theory Comput. 2014, 10 (6), 2306-2321.

https://doi.org/10.1021/ct500103h.

Luo, E.; Zhang, H.; Wang, X.; Gao, L.; Gong, L.; Zhao, T.; Jin, Z.; Ge, J.; Jiang, Z.; Liu, C.; Xing, W. Single-Atom Cr-N4 Sites Designed for Durable Oxygen Reduction Catalysis in Acid Media. Angew. Chemie - Int. Ed. 2019, 58 (36), 12469-12475. https://doi.org/10.1002/anie.201906289.

Yang, S.; Verdaguer-Casadevall, A.; Arnarson, L.; Silvioli, L.; 
Čolić, V.; Frydendal, R.; Rossmeisl, J.; Chorkendorff, I.; Stephens, I. E. L. Toward the Decentralized Electrochemical Production of H2O2: A Focus on the Catalysis. ACS Catal. 2018, 8 (5), 4064-4081. https://doi.org/10.1021/acscatal.8b00217.

(56) Mukerjee, S.; Srinivasan, S.; Soriaga, M. P.; McBreen, J. Role of Structural and Electronic Properties of Pt and Pt Alloys on Electrocatalysis of Oxygen Reduction: An In Situ XANES and EXAFS Investigation. J. Electrochem. Soc. 1995, 142 (5), 1409-1422. https://doi.org/10.1149/1.2048590.

(57) Escudero-Escribano, M.; Malacrida, P.; Hansen, M. H.; VejHansen, U. G.; Velazquez-Palenzuela, A.; Tripkovic, V.; Schiotz, J.; Rossmeisl, J.; Stephens, I. E. L.; Chorkendorff, I. Tuning the Activity of Pt Alloy Electrocatalysts by Means of the Lanthanide Contraction. Science (80-. ). 2016, 352 (6281), $73-$ 76. https://doi.org/10.1126/science.aad8892.

(58) Rhauderwiek, T.; Waitschat, S.; Wuttke, S.; Reinsch, H.; Bein, T.; Stock, N. Nanoscale Synthesis of Two Porphyrin-Based MOFs with Gallium and Indium. Inorg. Chem. 2016, 55 (11), 5312-5319. https://doi.org/10.1021/acs.inorgchem.6b00221.

(59) Mouchaham, G.; Abeykoon, B.; Giménez-Marqués, M.; Navalon, S.; Santiago-Portillo, A.; Affram, M.; Guillou, N.; Martineau, C.; Garcia, H.; Fateeva, A.; Devic, T. Adaptability of the Metal(III,IV) 1,2,3-Trioxobenzene Rod Secondary Building Unit for the Production of Chemically Stable and Catalytically ActIVe MOFs. Chem. Commun. 2017, 53 (54), 7661-7664. https://doi.org/10.1039/c7cc04215a.

(60) Jiang, H. L.; Feng, D.; Wang, K.; Gu, Z. Y.; Wei, Z.; Chen, Y. P.; Zhou, H. C. An Exceptionally Stable, Porphyrinic Zr MetalOrganic Framework Exhibiting PH-Dependent Fluorescence. $J$. Am. Chem. Soc. 2013, 135 (37), 13934-13938. https://doi.org/10.1021/ja406844r.

(61) Yaghi, O. M.; O'Keeffe, M.; Ockwig, N. W.; Chae, H. K.; Eddaoudi, M.; Kim, J. Reticular Synthesis and the Design of New Materials. Nature. 2003, pp 705-714. https://doi.org/10.1038/nature01650.

(62) Pratik, S. M.; Gagliardi, L.; Cramer, C. J. Engineering Electrical Conductivity in Stable Zirconium-Based PCN-222 MOFs with Permanent Mesoporosity. Chem. Mater. 2020, 32 (14), $6137-$ 6149. https://doi.org/10.1021/acs.chemmater.0c01847.

(63) Patwardhan, S.; Schatz, G. C. Theoretical Investigation of Charge Transfer in Metal Organic Frameworks for Electrochemical Device Applications. J. Phys. Chem. C 2015, 119 (43), 24238-24247.

https://doi.org/10.1021/acs.jpcc.5b06065.

(64) Cai, M.; Loague, Q.; Morris, A. J. Design Rules for Efficient Charge Transfer in Metal-Organic Framework Films: The Pore Size Effect. J. Phys. Chem. Lett. 2020, 11 (3), 702-709. https://doi.org/10.1021/acs.jpclett.9b03285.

(65) Liberman, I.; Shimoni, R.; Ifraemov, R.; Rozenberg, I.; Singh, C.; Hod, I. Active-Site Modulation in an Fe-Porphyrin-Based Metal-Organic Framework through Ligand Axial Coordination: Accelerating Electrocatalysis and Charge-Transport Kinetics. $J$. Am. Chem. Soc. 2020, 142 (4), 1933-1940. https://doi.org/10.1021/jacs.9b11355.

(66) Manz, T. A.; Sholl, D. S. Chemically Meaningful Atomic Charges That Reproduce the Electrostatic Potential in Periodic and Nonperiodic Materials. J. Chem. Theory Comput. 2010, 6 (8), 2455-2468. https://doi.org/10.1021/ct100125x.

(67) Manz, T. A. Introducing DDEC6 Atomic Population Analysis: Part 3. Comprehensive Method to Compute Bond Orders. RSC Adv. 2017, 7 (72), 45552-45581.

https://doi.org/10.1039/c7ra07400j. 


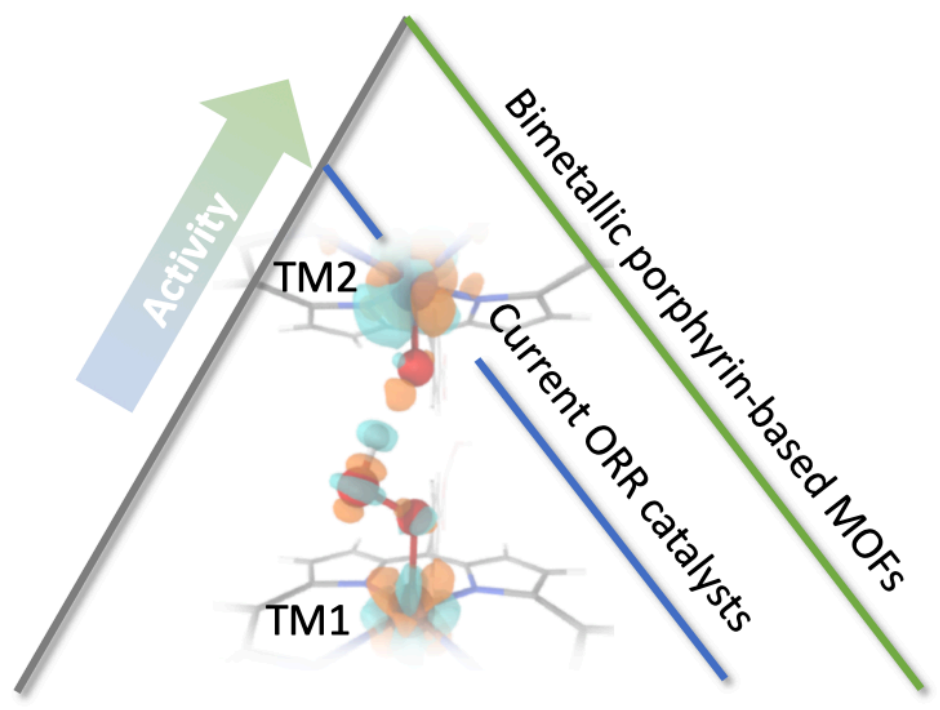

